\title{
Personal Exposure To Particulate Matter And Heart Rate Variability Among Informal Electronic Waste Workers At Agbogbloshie: A Longitudinal Study
}

Afua A. Amoabeng Nti ( $\sim$ aaamoabeng_nti001@st.ug.edu.gh )

University of Ghana

Thomas G. Robins

University of Michigan

John Arko Mensah

University of Ghana

Duah Dwomoh

University of Ghana

Lawrencia Kwarteng

University of Ghana

Sylvia Takyi

University of Ghana

Augustine Acquah

University of Ghana

Niladri Basu

McGill University

Stuart Batterman

University of Michigan

Julius N. Fobil

University of Ghana

\section{Research Article}

Keywords: Personal particulate matter, Informal e-waste recycling, PM2.5, PM10, PM 10-2.5, cardiac function, Heart rate variability, Agbogbloshie, Madina-Zongo

Posted Date: June 14th, 2021

DOI: https://doi.org/10.21203/rs.3.rs-555469/v1

License: (c) (i) This work is licensed under a Creative Commons Attribution 4.0 International License.

Read Full License 


\section{Abstract}

Background: Informal electronic waste recycling activities are major contributors to ambient air pollution, yet studies assessing the effects or relationship between direct/continuous exposure of informal e-waste workers to particulate matter and cardiovascular function are rare.

Methods: Repeated measurements of fractions of $\mathrm{PM}_{2.5}, \mathrm{PM}_{10-2.5}$, and $\mathrm{PM}_{10}$ in personal air of informal ewaste workers, $(n=142)$ and a comparable group $(n=65)$ were taken over a period of 20 months (March 2017 to November, 2018). Concurrently, 5-minute resting electrocardiogram was performed on each participant to assess resting heart rate variability indices. Linear mixed-effects models were used to assess the association between PM fractions and cardiac function.

Results: SDNN, RMSSD, LF, HF and LH/HF ratio were all associated with PM. Significant associations were observed for $\mathrm{PM}_{2.5}$ and MEANNN ( $\left.p=0.039\right), \operatorname{PM} 10$ and SDNN $(p=0.035)$ and PM $10-2.5$ and $\mathrm{LH} / \mathrm{HF}(p=0.039)$. A $10 \mu \mathrm{g} / \mathrm{m}^{3}$ increase in the concentrations of $\mathrm{PM}_{2.5}, \mathrm{PM}_{10-2.5}$, and $\mathrm{PM}_{10}$ in personal air was associated with reduced HRV indices and increased resting HR. A $10 \mu \mathrm{g} / \mathrm{m}^{3}$ per interquartile (IQR) increase in $\mathrm{PM}_{10-2.5}$ and $\mathrm{PM}_{10}$, decreased SDNN by $11 \%$ [ $\left.(95 \% \mathrm{Cl}:-0.002-0.000) ;(p=0.187)\right]$ and $34 \%$ [(95\% Cl:-0.002-0.001); $(p=0.035)]$ respectively. However, $\mathrm{PM}_{2.5}$ increased SDNN by $34 \%$ (95\% Cl: -1.32$0.64) ;(p=0.493)$. Also, $10 \mu \mathrm{g} / \mathrm{m}^{3}$ increase in $\mathrm{PM}_{2.5}, \mathrm{PM}_{10-2.5}$ and $\mathrm{PM}_{10}$ decreased RMSSD by $27 \%$ [(-1.34$0.79) ;(p=0.620)], 11 \%[(-1.73,0.95) ;(p=0.846)]$ and $0.57 \%[(-1.56-0.46) ;(p=0.255 \%)]$.

Conclusion: Informal e-waste workers are at increased risk of developing cardiovascular disease from cardiac autonomic dysfunction as seen in reduced HRV and increased heart rate.

\section{Introduction}

Increasing evidence implicates informal electronic waste (e-waste) recycling activities as a major contributor to ambient air pollution and yet studies describing the effects of continuous exposure to airborne particulates on cardiovascular (CV) function of informal e-waste workers are unavailable. Studies have associated air pollution with adverse CV outcomes such as increased heart rate and reduced heart rate variability (HRV) $(1-3)$, ventricular tachycardia $(4)$, vascular tone $(5,6)$ and morbidity and mortality due to cardiac arrhythmias $(7,8)$.

Reduced heart rate variability (HRV) is reported as an independent predictor of CV disease and death across diverse populations(9-11). It is a marker for poor health and increased risk for cardiac events (12). Reduced HRV is a prognostic factor of increased risk for all-cause and CV mortality(13-15).

Previous studies have related reduced HRV with CV outcomes such as myocardial infarction $(3,16,17)$ and coronary artery disease (18). Heart rate or rhythm abnormalities without hypoxia or respiratory distress in response to exposure to airborne particulates have been observed in many studies (19-21). Other studies have consistently shown that inhaled airborne $\mathrm{PM}_{2.5}$ and $\mathrm{PM}_{10}$ are associated with lower HRV in infants, the elderly, individuals with compromised CV integrity, as well as healthy individuals (12, 
22-26). Numerous studies have examined HRV in association with the total mass of $\mathrm{PM}_{2.5}$ and $\mathrm{PM}_{10}$ in various populations. A meta-analysis estimated the pooled effects of the total mass of $\mathrm{PM}_{2.5}$, finding a $1-2 \%$ decrease in HRV associated with each $10 \mu \mathrm{g} / \mathrm{m}^{3}$ increase in $\mathrm{PM}_{2.5}$ concentration (24). However, associations between $\mathrm{PM}_{2.5}$ and cardiovascular-related markers have been reported by only a few studies $(27,28)$. Few occupational studies have also established association between reduced HRV and exposure to airborne $\mathrm{PM}_{2.5}$ and $\mathrm{PM}_{10}(29-31)$.

E-waste recycling at Agbogbloshie in Accra, Ghana is conducted in an unhealthy and unsafe environment. The Blacksmith Institute, now Pure Earth has classified the site among the ten most polluted areas on earth (32). Due to the geographic layout, prevailing wind conditions, and intensity of smoke production due to open air burning of e-waste, there is a great public health concern regards to health implications of these exposures among e-waste workers and nearby populations. Open-air burning of cables and manual dismantling of lead-acid batteries are common practices, and these activities could result in significant environmental pollution and impact negatively on human health. Due to the improper processing of e-waste, workers are commonly exposed to toxic chemicals and are at increased risk of several health effects. Previous studies have documented evidence of several pollutants in the soil (33), water (34), and biological materials (blood, urine, breast milk) of both workers and by-standers (35-37). Recent air pollution data has reported very high concentrations of PM in ambient air $(38,39)$ and personal air of the waste recyclers(40-42). The levels were above the WHO-24hr air quality standards of $25 \mu \mathrm{g} / \mathrm{m}^{3}$ and $50 \mu \mathrm{g} / \mathrm{m}^{3}$ for $\mathrm{PM}_{2.5}$ and $\mathrm{PM}_{10}$ as well as the background levels of $30 \mu \mathrm{g} / \mathrm{m}^{3}$ for $\mathrm{PM}_{2.5}$ in the city of Accra. Informal e-waste workers at Agbogbloshie may be at higher risk of developing PM-related cardiovascular diseases or experiencing premature deaths due to inflammation-induced cardiac autonomic dysfunction. The link between inhalation of ambient air particles and effects on cardiac rhythm may be the induction of an inflammatory response in the lung with a subsequent release of chemical mediators that alter the autonomic nervous system's control of cardiac rhythm(43). Our study aimed to investigate the association between direct exposure to elevated levels of ambient particulates in the breathing zone of informal e-waste workers and alterations in cardiac autonomic function control. Specifically, this study was designed to determine whether high concentrations of PM is associated with the impaired cardiovascular function, as measured by the analysis of heart rate (HR), HRV and blood pressure.

\section{Materials And Methods}

\subsection{Study design and study area}

A longitudinal panel study design with repeated data collection at four sampling points for personal PM and health outcomes among e-waste workers at Agbogbloshie e-waste and comparable population was selected from populations at Madina Zongo was employed for this study. By the Ghana Statistical Service's definition (44), both Agbogbloshie and Madina Zongo are classified as slum communities. 
Round I of data collection was done from (March-May 2017), round II (August-October 2017), round III (January-April 2018) and round IV from (August-November 2018).

The Agbogbloshie e-waste recycling site is located in the central business district of Accra, Ghana's capital, surrounded by commercial centers, densely populated residential areas, the Odaw river and Korle lagoon. The Agbobgloshie electronic scrap yard, however, has become famous for its pollution and contamination of the environment, especially due to informal e-waste recycling activities. E-waste recycling processes include manual dismantling and open-air burning of e-waste fragments, enhanced by fire accelerants such as Styrofoam and tires to retrieve metals such as copper, aluminum, and gold for sale $(32,45,46)$. This continuous and unrestricted burning, however, produces plumes of black toxic smoke, containing several mixtures of hazardous substances such as PM, into the atmosphere(45). Informal e-waste workers and the Agbogbloshie community in general are at increased risk of several health conditions including e-waste related cardiovascular health effects from the continuous inhalation of airborne particulates present in the atmosphere.

The comparable or e-waste unexposed site, Madina Zongo, is also a densely populated suburb located at the La Nkwantanang Municipality; more than $15 \mathrm{~km}$ from the Agbogbloshie e-waste site. Majority of the residents of Madina Zongo, like Agbogbloshie, are migrants from northern Ghana, and are Moslems. The community members are mainly traders, engaged in a diverse mix of small-scale, informal businesses, mostly petty trading of items such as used clothing, charcoal, cold drinks, street foods, bicycle spare parts, staple foods, etc. However, no e-waste activity is conducted in this community (47).

\subsection{Study participants}

We recruited a total of two hundred and seven (207) participants, comprising one hundred and forty-two (142) informal e-waste workers and sixty-four (64) comparable subjects from Madina-Zongo into the study. At round I, we recruited one hundred and fifty-one (151) participants, comprising hundred (100) informal e-waste workers from Agbogbloshie and (fifty-one) 51 participants from Madina Zongo.

Originally, recruitment was planned at wave I only, however, due to the high participant attrition of $>30 \%$ at wave II, new participants were enrolled ( $n=42$ and $n=14$ for e-waste workers and the comparable population respectively), to replace those that were lost to follow-up. The study population comprised of male e-waste and a comparable population between the ages of 18 to 55 working at the Agbogbloshie ewaste site or resident at Madina Zongo. There are approximately 4,500-6,000 informal e-waste workers at the Agbogbloshie site who use rudimentary techniques and tools to recover valuable materials from waste electrical gadgets $(48,49)$. A recent detailed study of their time-activity diaries revealed that ewaste workers work from 7:00 am to $6: 00 \mathrm{pm}$ at an average of $10 \mathrm{~h}$ per day, 6 to 7 days a week (41). These workers are engaged in a myriad of job-specific tasks. The major job tasks include collecting and sorting e-waste.

\subsection{Data collection}


We measured $\mathrm{PM}\left(\mathrm{PM}_{10}\right.$, and $\left.\mathrm{PM}_{2.5}\right)$ in the breathing zone of each participant using a real-time optical pump (Aerocet 831, Met One Instruments, Inc, Oregon, USA ). We also performed 5-minute resting electrocardiograms (ECG) for each participant according to a standardized protocol (Task Force of The European Society of Cardiology and The North American \& Society of Pacing and Electrophysiology, 1996) to evaluate HRV. A questionnaire was also administered to elicit information on socio-demographic and other selected covariates. Three rounds (I, II, and III) of panel data collection were aligned to the prevailing weather patterns (dry, rainy, harmattan seasons) in the study areas. The comprehensive organizational procedures are documented elsewhere (41).

\subsubsection{Interview with a structured Questionnaire}

At enrolment, data on sociodemographic and economic factors (age, sex, religion, ethnicity, education, occupation, socioeconomic and marital status), detailed current and previous job history and exposures; home exposures including indoor cooking and biomass fuel use, pre-existing medical conditions, and lifestyle habits such as cigarette smoking and alcohol use were collected using a comprehensive questionnaire. Data on cigarette smoking included age at smoking initiation, duration of smoking, sticks smoked per day, current or ex-smoker defined as smoking cessation greater than a month's duration. Smokers were classified as current, ex-, or never-smokers. The questionnaire was administered by trained interviewers in a local dialect, Dagbani or Twi, or English according to the participant's preference. Limited interview guides were administered in subsequent follow-up data collection that explored possible changes in home and work exposures, and other cardiovascular and respiratory conditions.

\subsubsection{Personal Particulate Matter monitoring}

We measured personal particulates $\left(\mathrm{PM}_{10}, \mathrm{PM}_{10-2.5}\right.$, and $\left.\mathrm{PM}_{2.5}\right)$ in the breathing zone of each participant continuously per minute using a real time optical counter at a flow rate of $2.83 \mathrm{~L} / \mathrm{m}$. Personal level ambient temperature, relative humidity and barometric pressure were also measured every 1 minute using logging instrumentation (UX100-003 data logger; Onset Corporation, Bourne, MA, USA). All the measuring instruments were carried in a customized backpack with inlets in the breathing zone of participants for 4 hours of the working day, usually between $8 \mathrm{am}$ and $2 \mathrm{pm}$. As a quality control measure, PM concentrations were considered invalid when TSP exceeded $2000 \mu \mathrm{g} / \mathrm{m}^{3}$ (38). During round III however, the sampling duration was reduced to approximately 2-hrs due to the high levels of PM measured from PM laden (dust) harmattan winds.

\subsubsection{Heart Rate and Heart Rate Variability Measurement}

Heart rate variability is the physiological phenomenon of the variation in the time interval between consecutive heartbeats in milliseconds. Another name used for HRV is the 'R-R variability', where R is the point corresponding to the peak of the QRS complex (Fig. 1) of the ECG wave. The term 'NN' is used in place of 'RR' to show the 'normal' to 'normal' beats on the ECG (Task Force of the European Society of Cardiology and the North American Society of Pacing and Electrophysiology 1996). The QRS complex is the combination of three of the graphical deflections seen on a typical ECG. For this study we measured 
resting ECG using a 12-channel digital ECG recorder (Sonoscape Medical Corp, Shenzen, China), a continuous medical test device that measures heart rate, rhythm, and other abnormalities that may affect normal heart function, according to standard procedure $(50,51)$. HRV was measured with a variation in the RR intervals exhibited in a sequence of ECG sample using the short term measurement for five minutes under standard conditions. After a 5-10 minutes rest, each participant's ECG was recorded (sampling rate of $256 \mathrm{~Hz}$ per channel) for approximately 5 minutes with the subject lying supine and still. We used the best 5-consecutive-minute interval for the HRV calculations. The ECG digital recordings were processed, and heart rate and HRV indices were assessed using PC-based software, Kubios HRV premium software version 3.3 (Kubios HRV Software, Kuopio; Finland). Beats were automatically detected and assigned tentative annotations, which were then reviewed by an experienced technician to correct for any mislabeled beats or artifacts. HRV was assessed through time and frequency domain variables. Only normal-to-normal (NN) beat intervals were included in the analysis. We computed standard deviation of NN intervals (SDNN), the square root of the mean of the squared differences between adjacent NN intervals (RMSSD), high-frequency power (HF) $(0.15-0.4 \mathrm{~Hz})$, and low-frequency power (LF) (0.04-0.15 $\mathrm{Hz}$ ). We also estimated the LF/HF ratio to show the relative balance between the sympathetic and the vagal nerve activity (14). HRV was analyzed when RR intervals were $\geq 90 \%$ of all R-R intervals (52).

As shown in Fig. 1, QRS complex is the combination of three of the graphical deflections seen on a typical ECG. The QRS complex corresponds to the depolarization of the right and left ventricles of the human heart and contraction of the large ventricular muscles. The instantaneous heart rate (R-R interval) can be calculated from the time between any two QRS complexes. The P wave indicates atrial depolarization. It occurs when the sinus node creates an action potential that depolarizes the atria. The T wave occurs after the QRS complex and is a result of ventricular repolarization

\subsection{Ethical clearance}

Ethical clearance for the study was obtained from the ethical and protocol review committee of the College of Health Sciences (CHS-Et/M.4-P 3.9/2015-2016), University of Ghana and the University of Michigan's Institutional Review Board (IRB). Recruited participants provided a written informed consent endorsed by signature or thumbprint. Permissions were also obtained from the e-waste association and community leaders of the study sites

\subsection{Statistical procedures}

Data were analyzed using the statistical package STATA version 15 (Statacorp LLC, College Station, TX, USA). A descriptive analysis of the characteristics of the study participants was based on data obtained through the baseline questionnaire. Independent sample t-test was applied for the two-group comparisons of normally distributed data and the Mann Whitney $U$ test to the two group comparisons of non-normally distributed data. We used Analysis of variance (ANOVA) to compare the HRV, HR and blood pressure indices among the e-waste workers to the controls. We observed significant reductions in all the $\log _{10}$ transformed HRV indices (i.e., SDNN, RMSSD, MEANNN, LF, HF and ratio of LH/HF) for e-waste workers compared to controls across all three sampling periods (rounds I-III). Measures of HRV indices 
were $\log _{10}$-transformed to improve normality and stabilize variances for suitability to analyze data by mixed linear regression (53). Mixed models with a random participant effect and covariance structure were used to analyze the association between air pollutants ( $P M_{10}, \mathrm{PM}_{10-2.5}$ and $\mathrm{PM}_{2.5}$ ) and the ECG parameters taking into account the repeated measurements over time for each individual. We further included a linear term of each HRV measure in the model. The models were adjusted for age, BMI, job category, ambient temperature, barometric pressure, and relative humidity. Models were built for each ECG parameter separately. For effect modification, we considered body mass index $\left(B M I<25.0 \mathrm{~kg} / \mathrm{m}^{2}\right.$ smoking history (ex-smokers vs. never-smokers). Effect estimates are presented as percent change from the mean (arithmetic mean for all other ECG-variables) together with 95\%-confidence intervals based on an interquartile range increase in PM concentration. The associations were presented as percentage change in $\mathrm{HRV}$ indices per $10 \mu \mathrm{g} / \mathrm{m}^{3}$ increase in $\mathrm{PM}_{2.5}, \mathrm{PM}_{10-2.5}$ and $\mathrm{PM}_{10}$ with $95 \%$ confidence intervals (Cls). Analyses were performed using. $\mathrm{P}<0.05$ was considered statistically significant.

\section{Results}

\subsection{Sociodemographic and health characteristics of study participant}

As shown in Table 1, the participants were men with mean (SD) age of 27.87(8.14) years and ranged from 16 to 55 years. The comparable population was on average older (30.97 $\pm 9.92 \mathrm{yrs}$. vs $26.45 \pm 6.74$ years). More than half, $77(55 \%)$, of e-waste workers either had no formal or primary school education as compared to $46(62 \%)$ of the comparable population with high school education. Mean age, daily income, and educational level were significantly lower among the e-waste workers than the comparable population. Average body mass index (BMI) was $23.19 \pm 3.05 \mathrm{~kg} / \mathrm{m}^{2}$ and $23.75 \pm 3.44 \mathrm{~kg} / \mathrm{m}^{2}$ for e-waste workers and comparable population respectively, with no significant differences in BMI between the ewaste workers and comparable group $(p=0.100)$. The mean \pm SD systolic and diastolic blood pressure among the study participants was $124.34 \pm 15.52 \mathrm{mmHg}$ and $74.13 \pm 10.42 \mathrm{mmHg}$ respectively. When the blood pressure parameters were categorised based on the 2017 American Heart Association Hypertension guidelines, 94 (66.2\%) e-waste workers and 35(54.7\%) comparable group had normal blood pressure; whereas $14(21.9 \%)$ e-waste workers and 18 (12.7\%) individuals of the comparable group had elevated blood pressure. 11(17.2\%) e-waste workers versus 17(12.0\%) comparable group, and 4 (6.3\%) ewaste workers versus 13(9.2\%) comparable group $(p=0.198)$ were in stages 1 and stage 2 respectively. The frequency of cigarette smoking among e-waste workers and comparable group was 40 (25\%) and $6(10 \%)$ respectively $(p<0.001)$. Prevalence of pre-existing cardiovascular conditions including hypertension $3(4.0 \%)$ among e-waste workers compared to 8(19.1\%) among the non-e-waste workers; ( $p$ $\leq 0.001)$. Prevalence of diabetes mellitus among the e-waste and comparable population were $1(1.40 \%)$ versus $4(9.50 \%)$; $(p=0.005)$ respectively. None of the e-waste workers reported a previous history of dyslipidaemia compared to $5(11.90 \%)$ among the comparable population $(p<0.0001)$. There were also observable differences in the personal ambient barometric pressure between e-waste workers and 
comparable group [i.e., $750.89 \pm 33.6 \mathrm{mmHg}$ for e-waste workers versus $956.97 \pm 105.09 \mathrm{mmHg}$ for comparable group; $(p=0.014)$. Similar observations were made for ambient temperature [i.e., $37 \pm 2.21^{\circ} \mathrm{C}$ for e-waste workers versus $35.00 \pm 3.49^{\circ} \mathrm{C}$ for non-e-waste workers $(p<0.001)$. However, relative humidity levels between the e-waste workers and comparable group were not significantly different [i.e., $6.13 \pm$ $5.55 \%$ for e-waste workers versus $60.91 \pm 9.55 \%$ among comparable population $(p=0.229)$.

\section{Table 1: Socio-demographic and health Characteristics of study participants.}

Student t-test and Pearson Chi-square comparing the means and proportions between e-waste workers and a comparable population from Madina Zongo. *1US dollar (USD) is approximately 5.83 Ghanaian Cedi. Abbreviations: $\mathrm{SpO}_{2}$ - blood oxygen saturation. BMI- body mass index $\left(\mathrm{kg} / \mathrm{m}^{2}\right)$. $\mathrm{PM}$, relative humidity, barometric pressure, and ambient temperature were sampled for 4- hours of the workday. Bold $p$-values represent significant values $(p \leq 0.05)$. Variations in health outcome characteristics among ewaste and comparable population. Hypertension classification is based on 2017 AHA guidelines. Abbreviations: $\mathrm{SpO}_{2}$ - blood oxygen saturation. $\mathrm{BMI}$ - body mass index $\left(\mathrm{kg} / \mathrm{m}^{2}\right)$; \%predicted of FEV1Forced expiratory volume in one second; FVC- forced vital capacity; FEV1/FVC- the ratio of - Forced expiratory volume in one second and forced vital capacity; PEF-Peak expiratory flowrate; FEF25-75- forced expiratory flow between 25-75\%; Mean NN- mean normal to normal beats; SDNN- standard deviation of normal-to-normal; RMSSD; LF - low frequency; HF - high frequency; LF/HF ratio- the ratio of high frequency and low frequency. Bold $p$-values represent significant values $(p \leq 0.05)$.

\subsection{Variations in particulate matter concentrations in personal air of study participants}

The levels of $\mathrm{PM}_{2.5}, \mathrm{PM}_{10-2.5}$ and $\mathrm{PM}_{10}$ at each sampling period is shown in [Table S1]. The levels of $\mathrm{PM}_{2.5}, \mathrm{PM}_{10-2.5}$ and $\mathrm{PM}_{10}$ across the study period increased at each round with the highest concentrations recorded during the third sampling round (from Jan to March 2018), corresponding to the harmattan season (a period when dry and dust laden winds blows along the northwest coast of Africa from the Sahara Desert). The median/IQR concentrations of PM (2.5, $10-2.5$ and 10 $\mu \mathrm{m})$ among e-waste workers and comparable population (Table S1) over study time were consistently higher than the WHO air quality standards of $25 \mu \mathrm{g} / \mathrm{m}^{3}$ and $50 \mu \mathrm{g} / \mathrm{m}^{3}$ per 24-hour mean. Personal $\mathrm{PM}_{2.5}$ concentrations among ewaste workers for rounds I, II and III were $69.86 \pm 36.33 \mu \mathrm{g} / \mathrm{m}^{3}, 61.18 \pm 37.92 \mu \mathrm{g} / \mathrm{m}^{3}$ and $70.69 \pm$ $48.25 \mu \mathrm{g} / \mathrm{m}^{3}$; that of the comparable group were $34.88 \pm 0.14 .72 \mu \mathrm{g} / \mathrm{m}^{3}, 34.13 \pm 7.22 \mu \mathrm{g} / \mathrm{m}^{3}$ and $50.21 \pm$ $169.64 \mu \mathrm{g} / \mathrm{m}^{3}$ respectively. There were significant differences in concentrations of $\mathrm{PM}_{2.5}$ by rounds between the two groups; (I) $\mathrm{p}<0.001$, (II) $p<0.001$ and (III) $p=0.950$ respectively. Although the levels of $\mathrm{PM}_{2.5}$ was high at both study sites, higher concentrations (2x) of $\mathrm{PM}_{2.5}$ were recorded in the breathing zone of the e-waste workers compared to the comparable group. Similar trends were observed for the $\mathrm{PM}_{10-2.5}$ fraction across the study period I to III [i.e. $94.26 \pm 87.34 \mu \mathrm{g} / \mathrm{m}^{3}$ versus $68.23 \pm 63.31 \mu \mathrm{g} / \mathrm{m}^{3} ; p=$ $0.009] ;\left[48.88 \pm 84.68 \mu \mathrm{g} / \mathrm{m}^{3}\right.$ versus $\left.34.74 \pm 55.41 \mu \mathrm{g} / \mathrm{m}^{3} ; p=0.009\right]$ and $\left[54.30 \pm 126.38 \mu \mathrm{g} / \mathrm{m}^{3}\right.$ versus 
Total ( $(\mathrm{N}=207)$ E-waste

Workers

$(\mathrm{N}=142)$.

\section{Variable}

Age in years: mean \pm SD

Education (\%)

None

Primary

Middle/JHS

Secondary/SHS+

Marital Status

Single

Married

Daily Income (\%)*

$\leq$ GHS 20

GHS 20-40

GHS 41-60

GHS 61+

Indoor

cooking (\%)

\section{Lifestyle}

habits (\%)

Alcohol use (\%)

$27.87 \pm 8.14$

$26.45 \pm 6.74$

$30.97 \pm 9.92$

$<0.001$

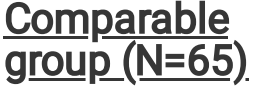

$\underline{P \text {-value }}$

Pyalue 


\section{weather}

variables

\begin{tabular}{lllll}
$\begin{array}{l}\text { Relative humidity } \\
(\%)\end{array}$ & $57.59 \pm 7.32$ & $56.13 \pm 5.51$ & $60.91 \pm 9.55$ & 0.229 \\
\hline $\begin{array}{l}\text { Barometric } \\
\text { pressure }(\mathrm{mmHg})\end{array}$ & $\begin{array}{l}7410.79 \\
\pm 63.40\end{array}$ & $7512.89 \pm 33.6$ & $7170 \pm 105.09$ & 0.037 \\
\hline $\begin{array}{l}\text { Ambient } \\
\text { temperature }\left({ }^{\circ} \mathrm{C}\right)\end{array}$ & $36.49 \pm 2.84$ & $37.15 \pm 2.21$ & $35.00 \pm 3.49$ & $<0.001$ \\
\hline $\begin{array}{l}\text { Self-reported } \\
\text { medical } \\
\text { History }(\%)\end{array}$ & & & & \\
\hline $\begin{array}{l}\text { Pulmonary } \\
\text { Tuberculosis }\end{array}$ & $2(1)$ & $2(1.42)$ & $0(0)$ & 0.86 \\
\hline Bronchial Asthma & $7(3.48)$ & $5(3.55)$ & $2(3.33)$ & 0.010 \\
\hline Hypertension & & & & 0.001 \\
\hline Yes & $11(9.3)$ & $15.2(12)$ & $8(19.1)$ & \\
\hline No & $90(76.3)$ & $84.6(66)$ & $33(78.6)$ & \\
\hline Diabetes Mellitus & & & & 0.005 \\
\hline Yes & $5(4.3)$ & $2.6(2)$ & $4(9.5)$ & \\
\hline No & $91(78.5)$ & $97.4(75)$ & $36(85.7)$ & \\
\hline Dyslipidaemia & & & & 0.000 \\
\hline Yes & $5(4.3)$ & $2.6(2)$ & $5(11.9)$ & \\
\hline No & $89(76.1)$ & $94.9(74)$ & $35(83.3)$ & \\
\hline Don't know & $23(19.7)$ & $2.6(2)$ & $2(4.8)$ & \\
\hline Medications & & & & \\
\hline
\end{tabular}

Medications (\%)

Anti-hypertensive

0.730

\begin{tabular}{lllll} 
Yes & $7(18.4)$ & $5(20)$ & $2(15.4)$ & \\
No & $31(81.6)$ & $20(80)$ & $11(84.6)$ & \\
Anti-diabetes & & & & \\
Yes & $2(5.7)$ & $1(4.2)$ & $1(9.1)$ & \\
No & $33(94.3)$ & $23(95.8)$ & $10(90.9)$ & \\
Statins & & & & 1.000 \\
Yes & $2(6.1)$ & $2(8.7)$ & $0(0)$ & \\
\hline
\end{tabular}




\begin{tabular}{lllll} 
No & $31(93.9)$ & $21(91.3)$ & $10(100)$ & \\
\hline $\begin{array}{c}\text { BMI }\left(\mathbf{k g} / \mathrm{m}^{2}\right): \\
\text { mean } \pm \text { SD }\end{array}$ & $23.37 \pm 3.19$ & $23.19 \pm 3.05$ & $23.75 \pm 3.44$ & 0.100 \\
\hline
\end{tabular}

\section{Blood pressure \\ (mmHg): mean \pm \\ SD}

\begin{tabular}{lcccc|}
$\begin{array}{l}\text { Systolic blood } \\
\text { pressure }\end{array}$ & $124.34 \pm 15.52$ & $122.31 \pm 12.62$ & $128.84 \pm 17.58$ & $\mathbf{0 . 0 1 0}$ \\
\hline $\begin{array}{l}\text { Diastolic blood } \\
\text { pressure }\end{array}$ & $74.13 \pm 10.42$ & $73.15 \pm 9.31$ & $75.98 \pm 12.55$ & 0.110 \\
\hline
\end{tabular}

\section{High Blood \\ pressure category \\ $(\%, n)$}

\begin{tabular}{lllll}
\hline Normal & $129(62.6)$ & $94(66.2)$ & $35(54.7)$ & 0.198 \\
\hline Elevated & $32(15.5)$ & $14(21.9)$ & $18(12.7)$ & \\
\hline Stage 1 & $28(13.6)$ & $11(17.2)$ & $17(12)$ & \\
\hline Stage 2 & $17(8.3)$ & $4(6.3)$ & $13(9.2)$ & \\
\hline $\begin{array}{l}\text { Resting pulse rate } \\
\text { (bpm): mean } \pm\end{array}$ & $74.1 \pm 12.1$ & $74.2 \pm 12.6$ & $74.1 \pm 13.6$ & 0.960 \\
SD
\end{tabular}

\section{Resting pulse rate category $(\%, n)$}

\begin{tabular}{lcccc}
\hline $\begin{array}{l}<85 \mathrm{bpm} \\
\text { (Normal) }\end{array}$ & $157(75.85)$ & $107(75.35)$ & $50(76.92)$ & 0.806 \\
\hline $\begin{array}{l}\text { >85 bpm } \\
\text { (Abnormal) }\end{array}$ & $50(24.15)$ & $35(24.65)$ & $15(23.08)$ & \\
\hline $\begin{array}{l}\text { Blood oxygen } \\
\text { saturation (\%): } \\
\text { mean } \pm \text { SD }\end{array}$ & $96.56 \pm 3.23$ & $96.34 \pm 3.64$ & $97.06 \pm 1.94$ & $\mathbf{0 . 0 1 9}$ \\
\hline
\end{tabular}

\section{Blood oxygen \\ saturation \\ category $(\%, n)$}

\begin{tabular}{lllll}
$\geq 95 \%$ (Normal) & $94.7(195)$ & $93.7(133)$ & $96.9(62)$ & 0.343 \\
\hline$<95 \%$ (Abnormal) & $11(5.3)$ & $9(6.3)$ & $2(3.1)$ & \\
$\begin{array}{l}\text { Heart rate } \\
\text { variability } \\
\text { (Mean } \pm \text { SD) }\end{array}$ & & & & \\
\hline Log LF & $10.4 \pm 1.7$ & $11.1 \pm 0.7$ & $10 \pm 2.0$ & $\mathbf{\leq 0 . 0 0 1}$ \\
\hline
\end{tabular}




\begin{tabular}{lllll} 
Log HF & $9.8 \pm 2$ & $9.2 \pm 2.2$ & $10.8 \pm 0.9$ & $\mathbf{5 0 . 0 0 1}$ \\
\hline LH/ HF ratio & $2.4 \pm 2.2$ & $2.8 \pm 2.3$ & $1.8 \pm 1.4$ & $\mathbf{0 . 0 0 4}$ \\
\hline Log SDNN & $5.4 \pm 0.6$ & $5.2 \pm 0.7$ & $5.8 \pm 3.0$ & $\mathbf{5 0 . 0 0 1}$ \\
\hline Log RMSSD & $5.2 \pm 0.8$ & $4.9 \pm 0.8$ & $5.7 \pm 0.3$ & $\mathbf{\leq 0 . 0 0 1}$ \\
\hline MEANRR & $474.8 \pm 159.8$ & $410.7 \pm 142.6$ & $585.7 \pm 123.6$ & $\mathbf{\leq 0 . 0 0 1}$
\end{tabular}

$31.59 \pm 383.81 \mu \mathrm{g} / \mathrm{m}^{3} ; p=0.960$ ] respectively. Also, higher levels of $\mathrm{PM}_{10}$ were consistently observed among e-waste workers than comparable group [(214.43 $\pm 154.46 \mu \mathrm{g} / \mathrm{m}^{3}$ vs. $118.12 \pm 79.99 \mu \mathrm{g} / \mathrm{m}^{3} ; p \leq$ $0.001),\left(173.49 \pm 96.12 \mu \mathrm{g} / \mathrm{m}^{3}\right.$ vs. $\left.99.35 \pm 107.1 \mu \mathrm{g} / \mathrm{m}^{3} ; p \leq 0.001\right)$, and $181.64 \pm 104.46 \mu \mathrm{g} / \mathrm{m}^{3}$ vs. 395.57 $\left.\left.\pm 412 \mu \mathrm{g} / \mathrm{m}^{3} ; p=0.998\right)\right]$. Description of personal levels of PM among study participants is already published (40).

\subsection{Variations in heart rate variability indices, and resting heart rate among study participants}

Comparison of HRV indices among study participants is presented in [Table 2]. These values are the means (SD) of the test results for each individual, averaged over the round of the study period. Mean values are presented showing the differences between the informal e-waste workers and the comparable population during rounds I and II, there was significant evidence of reduction in $\log _{10}$ SDNN among ewaste workers compared to the comparable group [( $5.23 \pm 0.68$ vs $4.88 \pm 0.08) ; p=\leq 0.001$, and ( $5.28 \pm$ 0.67 vs. $5.60 \pm 0.55) ; p=\leq 0.001$ ]. However, during round III, the control population showed a lower mean $\log _{10}$ SDNN compared to the e-waste workers (5.02 \pm 0.82 vs $\left.5.34 \pm 0.67\right) ; p=0.030$.

Resting HR between e-waste workers and comparable group at round I was similar (73.91 \pm 10.16 vs.74.09 \pm 13.63$) ; p=0.960$ and III (73.91 \pm 10.16 vs74.00 \pm 12.67$) ; p=0.960$, but controls had lower mean HR during round II (70.16 \pm 10.64 vs. $69.52 \pm 10.54) ; p=0.050$. 
Table 2

Variation in Heart rate variability among e-waste and non-e-waste workers

Variable

E-waste -

workers

$(n=142)$
Comparable group $(n=$ 65)

p-value

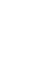

\section{5-min resting Heart Rate Variability, Mean \\ (SD)}

RI (Dry season)

MeanNN

Log SDNN

$4.23 \pm 0.68$

$5.88 \pm 0.08$

$\leq .001$

Log RMSSD

$4.88 \pm 0.84$

$5.01 \pm 84.52$

$\leq .001$

Log LF

$9.98 \pm 1.98$

$11.12 \pm 0.68$

$\leq .001$

Log HF

$9.25 \pm 2.25$

$10.77 \pm 0.91$

$\mathbf{5} 001$

LF/HF ratio

$2.75 \pm 2.33$

$1.84 \pm 1.66$

0.004

\section{R II (Rainy season)}

Mean NNN

Log SDNN

$5.28 \pm 0.67$

$5.60 \pm 0.55$

$\mathbf{0 . 0 0 1}$

Log RMSSD

$4.85 \pm 0.93$

$5.48 \pm 0.74$

$\mathbf{0 . 0 0 1}$

Log LF

$10.00 \pm 2.07$

$10.71 \pm 1.53$

0.030

Log HF

$9.19 \pm 2.49$

$10.28 \pm 1.83$

0.010

LF/HF ratio

$3.50 \pm 5.12$

$1.85 \pm 1.31$

0.010

\section{R III (Harmattan season )}

Mean NNN

Log SDNN (ms)

$5.02 \pm 0.82$

$5.34 \pm 0.67$

0.030

Log RMSSD (ms)

$4.55 \pm 0.94$

$5.05 \pm 0.83$

0.010

Sampling rounds were aligned to annual seasonal changes in study area, i.e. R I, II and III were aligned to the dry, rainy and harmattan respectively. Abbreviations: R- round; Mean NN- mean normal to normal beats ; SDNN- standard deviation of normal-to-normal; RMSSD; LF - low frequency; HF - high frequency -; LF/HF ratio- ratio of high frequency and low frequency. Bold $p$-values are significant at $p$ $\leq 0.05$. 


\begin{tabular}{|c|c|c|c|}
\hline Variable & $\begin{array}{l}\text { E-waste - } \\
\text { workers } \\
(n=142)\end{array}$ & $\begin{array}{l}\text { Comparable group }(n= \\
65)\end{array}$ & p-value \\
\hline $\log \operatorname{LF}\left(m s^{2}\right)$ & $9.36 \pm 2.38$ & $10.22 \pm 1.71$ & 0.030 \\
\hline Log HF (m/s) & $8.45 \pm 2.57$ & $9.57 \pm 2.06$ & 0.010 \\
\hline LF/HF ratio & $3.60 \pm 2.93$ & $2.46 \pm 1.81$ & 0.010 \\
\hline \multicolumn{4}{|c|}{ Heart rate (beats/min), Mean (SD) } \\
\hline Round I & $73.91 \pm 10.16$ & $74.09 \pm 13.63$ & 0.960 \\
\hline Round II & $70.16 \pm 10.64$ & $69.52 \pm 10.54$ & 0.050 \\
\hline Round III & $73.91 \pm 10.16$ & $74.00 \pm 12.67$ & 0.960 \\
\hline \multicolumn{4}{|c|}{$\begin{array}{l}\text { Sampling rounds were aligned to annual seasonal changes in study area, i.e. R I, II and III were aligned } \\
\text { to the dry, rainy and harmattan respectively. Abbreviations: R- round; Mean NN- mean normal to } \\
\text { normal beats; SDNN-standard deviation of normal-to-normal; RMSSD; LF - low frequency; HF - high } \\
\text { frequency -; LF/HF ratio- ratio of high frequency and low frequency. Bold p-values are significant at } p \\
\leq 0.05 \text {. }\end{array}$} \\
\hline
\end{tabular}

\subsection{Association between particulate matter exposure and heart rate variability indices}

Following the conventional procedures in the HRV protocols, all HRV indices were log transformed. The primary theory in this study was that increasing concentrations of $\mathrm{PM}_{2.5}, \mathrm{PM}_{10-2.5}$ and $\mathrm{PM}_{10}$ levels in the breathing zone of e-waste workers is associated with decrease in HRV indices. The crude and adjusted estimates of PM exposure on HRV is presented in [Table 3]. The effect estimates for the association between $\mathrm{PM}_{2.5}, \mathrm{PM}_{10-2.5}$ and $\mathrm{PM}_{10}$ and the HRV indices (i.e. SDNN, RMSSD, LF, HF and HF/LF ratio) were mixed.

Results from the adjusted models showed that SDNN (the standard deviation of the normal-to-normal) was negatively associated with $\mathrm{PM}$. A $10 \mu \mathrm{g} / \mathrm{m}^{3}$ per interquartile (IQR) increase $\mathrm{PM}_{10-2.5}$ and $\mathrm{PM}_{10}$, decreased SDNN by $11 \%$ (95\% Cl: $-0.002-0.000) ; p=0.187$ and $34 \%$ (95\% Cl:-0.002-0.001); $p=0.035$ respectively. However, $\mathrm{PM}_{2.5}$ increased SDNN by $34 \%(95 \% \mathrm{Cl}:-1.32-0.64) ; p=0.493$ and the association was statistically insignificant. SDNN represents an estimation of the total HRV over a specified time (in milliseconds).

Also, a $10 \mu \mathrm{g} / \mathrm{m}^{3}$ increase in $\mathrm{PM}_{2.5}, \mathrm{PM}_{10-2.5}$ and $\mathrm{PM}_{10}$ decreased RMSSD by $27 \%$ [(-1.34-0.79); $p=0.620$, $11 \%(-1.73,0.95) ; p=0.846$ and $0.57 \%(-1.56-0.46) ; p=0.2551]$ respectively after adjusting for selected covariates. However, the associations were not significant. RMSSD estimates short-term (high frequency) components of HRV which reflects the relative influence of the parasympathetic nervous system. In the 
adjusted models, a $10 \mu \mathrm{g} / \mathrm{m}^{3}$ increase in $\mathrm{PM}_{2.5}, \mathrm{PM}_{10-2.5}$ and $\mathrm{PM}_{10}$ range, decreased MEANNN by $76 \%$ (95\% Cl: $-1.48,-0.04) ; p=0.039$. The association was statistically significant. However, $\mathrm{PM}_{10-2.5}$ and $\mathrm{PM}_{10}$ increased MEANNN by $14 \%$ (95\% Cl: $-0.08-0.25) ; p=0.218$ and $5.0 \%(95 \% \mathrm{Cl}:-0.09-0.19) ; p=0.591$ respectively.

After adjusting the model for selected covariates, $\mathrm{PM}_{2.5}, \mathrm{PM}_{10-2.5}$ and $\mathrm{PM}_{10}$ decreased $\mathrm{LF}$ by $0.7 \%$ ( $95 \%$ Cl:-0.004- 0.023); $p=0.154,0.6 \%$ (-0.101-0.002); $p=0.479$ and $0.4 \%$ (95\% Cl: $-0.021-0.010), p=0.213$ respectively. In the adjusted model, $\mathrm{PM}_{2.5}$, increased HF by $1.0 \%$ (95\% Cl:-0.005-0.025); $\left.p=0.199\right)$, whilst both $\mathrm{PM}_{10-2.5}$ and $\mathrm{PM}_{10}$ decreased $\mathrm{HF}$ by $\left.0.4 \%(95 \% \mathrm{Cl}-0.009-0.001) ; p=0.107\right)$ and $0.5 \%(95 \%$ Cl:-0.012-0.001); $p=0.104$ ). For every $10 \mu \mathrm{g} / \mathrm{m}^{3} / \mathrm{IQR}$ increase in $\mathrm{PM}_{2.5}$, the LF/HF ratio increased by $6.6 \%$ (95\% Cl:-0.015- 0.147); $p=0.110$. $\mathrm{PM}_{10-2.5}$ and $\mathrm{PM}_{10}$, however decreased LF/HF ratio by $0.1(-0.027$ $-0.025) ; p=0.932$ and $1.0 \%$ (95\% Cl:-0.040-0.020); $p=0.522$. 
Table 3

Association between particulate matter exposure and heart rate variability indices

\begin{tabular}{|c|c|c|c|c|}
\hline Variable & Crude & & Adjusted & \\
\hline Heart rate variability (\%) & $\beta[95 \% \mathrm{Cl}]$ & P-value & $\beta[95 \% \mathrm{Cl}]$ & P-value \\
\hline \multicolumn{5}{|l|}{ MeanNN } \\
\hline $\mathrm{PM}_{2.5}$ & $-0.54(-0.99,-0.097)$ & 0.017 & $-0.76(-1.48,-0.04)$ & 0.039 \\
\hline $\mathrm{PM}_{10-2.5}$ & $0.01(-0.12,0.12)$ & 0.989 & $0.14(-0.08,0.25)$ & 0.218 \\
\hline $\mathrm{PM}_{10}$ & $0.05(-0.09,0.19)$ & 0.448 & $0.05(-0.14,0.25)$ & 0.591 \\
\hline \multicolumn{5}{|l|}{ SDNN } \\
\hline $\mathrm{PM}_{2.5}$ & $-0.35(-0.71,0.01)$ & 0.059 & $0.34(-1.32,0.64)$ & 0.493 \\
\hline $\mathrm{PM}_{10-2.5}$ & $0.63(0.11,1.13)$ & 0.017 & $-0.11(-1.73,0.95)$ & 0.846 \\
\hline $\mathrm{PM}_{10}$ & $-0.52-0.95,-0.93)$ & 0.017 & $-0.34(-1.32,0.64)$ & 0.035 \\
\hline \multicolumn{5}{|l|}{ RMSSD } \\
\hline $\mathrm{PM}_{2.5}$ & $0.49(-0.86,0.33)$ & $\leq 0.001$ & $-0.27(-1.34,0.79)$ & 0.620 \\
\hline $\mathrm{PM}_{10-2.5}$ & $0.93(-0.41,1.46)$ & $\leq 0.001$ & $-0.01(-1.26,1.28)$ & 0.275 \\
\hline $\mathrm{PM}_{10}$ & $-0.77(-0.86,-1.24)$ & 0.009 & $-0.57(-1.56,0.46)$ & 0.255 \\
\hline \multicolumn{5}{|l|}{ LF } \\
\hline $\mathrm{PM}_{2.5}$ & $-0.002(-0.009,0.004)$ & 0.507 & $-0.007(-0.004,0.023)$ & 0.154 \\
\hline $\mathrm{PM}_{10-2.5}$ & $0.003(-0.006,0.012)$ & 0.552 & $-0.006(-0.101,0.002)$ & 0.479 \\
\hline $\mathrm{PM}_{10}$ & $0.002(-0.006,0.012)$ & 0.533 & $-0.004(-0.021,0.010)$ & 0.213 \\
\hline \multicolumn{5}{|l|}{ HF } \\
\hline $\mathrm{PM}_{2.5}$ & $0.002(-0.005,0.010)$ & 0.521 & $0.010(-0.005,0.025)$ & 0.199 \\
\hline $\mathrm{PM}_{10-2.5}$ & $0.001(-0.002,0.002)$ & 0.903 & $-0.004(-0.009,0.001)$ & 0.107 \\
\hline $\mathrm{PM}_{10}$ & $-0.001(-0.004,0.001)$ & 0.310 & $-0.005(-0.012,0.001)$ & 0.104 \\
\hline \multicolumn{5}{|l|}{ LF/HF } \\
\hline $\mathrm{PM}_{2.5}$ & $0.008(-0.002,0.019)$ & 0.117 & $0.020(-0.256,0.301$ & 0.867 \\
\hline $\mathrm{PM}_{10-2.5}$ & $0.013(0.001,-0.245)$ & 0.035 & $0.004(-0.402-0.032)$ & 0.030 \\
\hline
\end{tabular}




\begin{tabular}{|lllll|}
\hline Variable & Crude & \multicolumn{2}{l|}{ Adjusted } & \\
\hline $\mathrm{PM}_{10}$ & $0.015(-0.029-0.011)$ & 0.035 & $0.003(-0.273-0.034)$ & 0.836 \\
\hline HR (beats/min) & & & & \\
$\mathrm{PM}_{2.5}$ & $0.014(-0.023,0.051)$ & 0.462 & $0.066(-0.015,0.147)$ & 0.110 \\
$\mathrm{PM}_{10-2.5}$ & $0.001(-0.007,0.009)$ & 0.862 & $-0.001(-0.027,0.025)$ & 0.932 \\
$\mathrm{PM}_{10}$ & $0.002(-0.013,0.009)$ & 0.742 & $-0.010(-0.040,0.020)$ & 0.522 \\
\hline
\end{tabular}

Controlled for age, BMI (overweight), job category, smoking status, alcohol use, study location, and weather variables (ambient temperature and relative humidity). Bolden $p$-value is significant at $p \leq 0.05$.

\subsection{Effects of selected covariates on the association of PM exposure on HRV indices}

The associated effects of PM exposure and selected covariates is presented in [Table S2]. E-waste Job tasks were negatively associated with all HRV indices. A $10 \mu \mathrm{g} / \mathrm{m}^{3}$ increase in PM decreased RMSSD by 98\% (95\% Cl: $-1.62,-0.33), 64 \%$ (95\% Cl: $-1.28,-0.01), 62 \%$ (95\% Cl: $-0.94,-0.29)$ and 59\% (95\% Cl: -0.96 , 0.21 ) among e-waste collectors, sorters, dismantlers and burners respectively and these associations were highly significant $(p \leq 0.001 ; p \leq 0.001 ; p=0.05 ; p \leq 0.001)$. SDNN were equally reduced by $37 \%$ (95\% Cl: $-0.82,0.08)$ among collectors, $34 \%$ (95\% Cl: $-0.61,-0.08)$ among burners, $29 \%$ (95\% Cl: $(-0.53$, $0.07)$ among dismantlers, and $29 \%$ ( $95 \% \mathrm{Cl}:(-0.73,0.16)$ among sorters. LF was also reduced across all job categories except among sorters, where we observed an increase of $26 \%(95 \% \mathrm{Cl}:-1.33,1.85) ; p=$ 0.75. Among burners, collectors and dismantlers, LF reduced by $114 \%(95 \% \mathrm{Cl}:-2.08,-0.19), p=0.02 ; 94 \%$ (95\% Cl: $-1.74,-0.13), p=0.02$ and $63 \%(95 \% \mathrm{Cl}:-2.24,0.98), p=0.04$ respectively. $\mathrm{HF}$ values were reduced across all e-waste categories. HF decreased among burners by $126 \%(95 \% \mathrm{Cl}:-2.35,-0.16), p=0.03 ; 99 \%$ (95\% Cl: -1.92,-0.06), $p=0.04$ ] among dismantlers, $15 \%$ (95\% Cl: $-1.99,1.69), p=0.88$ among sorters and $163 \%$ (95\% Cl: $-3.49,0.23), p=0.09$ among sorters. The relationship of HRV indices with age was variable. Generally increased age is associated with a marginal increased in RMSSD [(95\% Cl: $-0.01,0.02) ; p=0.58]$ and SDNN [(95\% Cl: $-0.01,0.01) ; p=0.97]$, by $1.0 \%$ and decreased LF [(95\% Cl: $-0.04,0.04) ; p=0.97]$ and HF $[95 \% \mathrm{Cl}:-0.05,0.05) ; p=0.96]$ by $1.0 \%$. Overweight $\left(\mathrm{BMl}>25 \mathrm{~kg} / \mathrm{m}^{2}\right)$ was associated with decreases in RMSSD, SDNN, LF and LF [i.e. $16 \%$ (95\% Cl: $-0.47,0.16), p=0.33 ; 11 \%(95 \% \mathrm{Cl}:-0.33,0.12), p=0.34 ; 64 \%$ $(95 \% \mathrm{Cl}:-1.43,0.15), \mathrm{p}=0.11 ; 27 \%(95 \% \mathrm{Cl}:-1.18,0.65), \mathrm{p}=0.57)$ respectively]. The associations were insignificant. Indoor cooking was also associated with negative but insignificant associations with HRV. Indoor cooking reduced RMSSD by $1 \%(95 \% \mathrm{Cl}:-0.32,0.31) ; \mathrm{p}=0.97$, SDNN by $4 \%(95 \% \mathrm{Cl}:-0.26,0.18): p$ $=0.72$, LF by $13 \%$ (95\% Cl: $-0.91,0.66) ; p=0.75$ and HF by $18 \%(95 \% \mathrm{Cl}:-0.72,1.09) ; p=0.69)$.

\section{Discussion}


Occupational exposure to PM have been associated with adverse cardiovascular health outcomes. It is established that both acute and chronic exposures to PM are related to CVDs (43). We conducted a longitudinal cohort study that assessed the association of personal ambient $\mathrm{PM}_{2.5}, \mathrm{PM}_{10}-2.5$, and $\mathrm{PM}_{10}$ on the cardiac autonomic function of healthy informal e-waste workers. We observed consistent reductions in $H R V$, and $H R$ across the sampling periods due to the direct exposure to $P M(2.5,10-2.5$ and $10 \mu \mathrm{m}$ ) among the informal e-waste workers. We observed a consistently decreased HRV indices (when values were $\log _{10}$ transformed over time and frequency) among informal e-waste workers across the three sampling periods compared to the control group. In evaluating the percentage change of PM $(2.5$, 10 - 2.5 and $10 \mu \mathrm{m}$ ) exposure on HRV over time, we observed a non- significant decrease in HRV among ewaste workers of different job task after adjusting the models for covariates such as age, sampling location, sampling round, personal ambient temperature, barometric pressure and relative humidity.

The influence of the cardiac autonomic nervous system in balancing the cardiovascular system during rest and work can be assessed with HRV and, in occupational health, this is commonly describe using the frequency domain and time domain HRV parameters (e.g. RMSSD, HR MEANNN, LF, HF, SDNN) (54). RMSSD reflects the beat-to-beat variance in HR and is the primary time-domain measure used to estimate the vagal nerve -mediated changes reflected in HR. MEANNN measures the variations in R-R intervals over time and the response of the CVS to diverse environmental stimuli and workloads; an abnormal beats reflect cardiac dysfunction. The LF band $(0.04-0.15 \mathrm{~Hz})$ is typically recorded over a minimum of 2 minutes period and reflects the respiratory-related efferent vagal - mediated influences. HF is a frequencydomain HRV statistic that summarizes the power spectral density of the heartbeat from 0.15 to 0.4 hertz and is an estimator of parasympathetic autonomic control. A low LF/HF ratio indicates high parasympathetic dominance; in contrast, a high LF/HF ratio reflects sympathetic dominance, which occurs in fight-or-flight situations. The SDNN, which shows the10-second as well as the fast fluctuations in heart rate, reflects the sympathetic and parasympathetic involvement.

The reduction in HRV indices among participants may be as a result of external factors (such as climate conditions, job related conditions, exposure harmful substances), lifestyle habits, diseases and physiological factors as shown in another study (55). The study evaluated the effect of some of these factors (identified as covariates) on HRV and results showed a reduction in HRV. The consistent reduction in HRV parameters among e-waste workers at each sampling period demonstrates that they have less favourable health and an increased risk of arrhythmias (56) than comparable group and this may be linked to their job task and exposure to PM generated as shown by covariate analysis. The high reduction of RMSSD among e-waste collectors may partly be explained by the potential exposure to multiple pollutants. Collectors typically trek around town, scavenging for scrubs and wasted EEEs. Concurrent exposure to vehicular exhaust particles, smoke from biomass, entrained dusts and other sources of PM be accountable for the observed results.

Studies reporting PM-associated reductions in HRV have been conducted among elderly populations and patients with primarily lung diseases such as COPD $(57)$ and asthmatics $(58,59)$. PM-associated reductions in HRV effects have been associated with all PM fractions, although some inconsistencies 
between the studies do exist. Albeit this, some inconsistencies have been observed in studies among both young and healthy subjects in terms of the direction of the HRV changes $(1,60,61)$.

Previous occupational studies have shown a negative association between increased $\mathrm{PM}_{2.5}$ exposure and variations in the autonomic function as indicated by changes in HRV (measured in time and frequency domains). In most of the studies, measures of HRV were reduced, suggesting an overall trend toward withdrawal of parasympathetic tone. For example, Wilson and colleagues, (30) examined the associated effects of $\mathrm{PM}_{2.5}$ exposure on HRV indices among restaurant and bar workers $(n=14)$. They found that for every $10 \mu \mathrm{g} / \mathrm{m}^{3}$ increase in $\mathrm{PM}_{2.5}$ decreased SDNN by $2.66 \%$ and RMSSD by $3.79 \%$. In our study recorded similar findings except that the SDNN and RMSSD percentage decreases were greater, thus, $10 \mu \mathrm{g} / \mathrm{m}^{3}$ per IQR increase in $\mathrm{PM}_{2.5}$ increased SDNN decreased by $35 \%$ and RMSSD by $27.0 \%$. Also, they observed an increase in post shift HR to 108 beats/min. from baseline. In a cross sectional study among vehicle maintenance workers $(n=5)$ who were exposed to $P M_{2.5}$, Eninger \& Rosenthal (62) reported decreases in SDNN, TP, RMSSD and HF with increasing $\mathrm{PM}_{2.5}$, but the associations were statistically insignificant except for total spectral power $(p<0.05)$. We observe marginal decreases in $\mathrm{HF}$ of $1.0 \%(p=0.199)$. In another panel study conducted among boiler construction workers $(n=36)$ exposed to $\mathrm{PM}_{2.5}$ in welding fumes in the United States of America high concentrations of metal component of $\mathrm{PM}_{2.5}$ in welding fumes was associated with reduced night time RMSSD (19).

In a longitudinal cohort study among boiler construction workers $(n=39)$ who were exposed to high $\mathrm{PM}_{2.5}$ concentrations (mean $697 \mu \mathrm{g} / \mathrm{m}^{3}$ ), it was found that $1 \mathrm{mg} / \mathrm{m}^{3}$ increase in $\mathrm{PM}_{2.5}$ was associated with $2.26 \%$ decrease in 5-min SDNN and $1.02 \%$ increase in HR (27), and correlation between $\mathrm{PM}_{2.5}$ and SDNN was statistically significant. Their observation may be attributed to the high average PM exposures, which were over 10 times greater than the levels observed in this study. Riediker (60) also demonstrated decreases in HR among highway patrol troopers exposed to PM in their cars, while subjects exposed aboard a diesel bus also experienced increased HR (1). Some epidemiological studies have reported immediate cardiovascular system responses, within hours of exposure to PM (12), but more often same day delayed responses were detected $(22,63-65)$, suggesting that PM - induced effects on autonomic function seem to accumulate in association with prolonged elevated air pollution.

Because of the small sample size in this study, and the relatively low level of exposure, no definitive conclusion could be drawn about the relationship of occupational exposure to $\mathrm{PM}_{2.5}$ and $\mathrm{HRV}$ in normal subjects. In addition, this study, as in many of the previous studies, current study did not further investigate the chemical composition of $\mathrm{PM}_{2.5}$. Particulate matter composition differs by source and some are more toxicologically active than others. Additionally, aerosol composition likely varies between work, transit, ambient, and home environments. Initial research has suggested an association of HRV with the metallic component of $\mathrm{PM}_{2.5}$ in the workplace $(27,29)$. In comparing occupational studies of $\mathrm{PM}_{2.5}$ and $\mathrm{HRV}$ in worker populations with those done in the general population, these differences, as well as the differences in the age distribution and other characteristics of the respective populations, must be 
considered. Further studies of the effects of workplace $\mathrm{PM}_{2.5}$ on HRV should examine the role of exposure level and exposure composition in larger and more varied worker populations.

\section{Conclusion}

Overall, our study is consistent with several epidemiological studies which support the hypothesis that ambient concentrations of PM represent an environmental stressor that could alters autonomic balance, leading to ischemia, fatal arrhythmia, or myocardial infarctions. At this point in time, it seems that the most important challenge is to better understand the mechanisms and to pursue further the possibility that cardio-protective therapy and/or dietary supplementations can abrogate the adverse effects of PM in susceptible populations. What are these constraints

\section{Strength And Limitations Of Study}

As far as we know, this is the first longitudinal study examining the effects of e-waste recycling associated PM in the breathing zone of workers on workers' HRV in occupational environment. Second, we measured real-time personal air samples for the concentration of PM in the breathing zone of the ewaste workers; which gives a more accurate measurement. This method is not used routinely due to the fact that personal monitoring pumps could become a hindrance to the subjects' work tasks. We overcome this challenge with the use of light weight optical particle counter pumps assembled in customized backpacks, with inlets in the breathing zone, which could be worn comfortably by participants.

Performing real time ECG in an informal work environment is difficult due to noise, and inappropriate environmental constraints. Despite several logistics and space limitation, a temporary onsite clinic was erected to create the actively performed real time ECG to assess cardiac function among e-waste workers.

Our study also had some limitations. Ambient PM was the only contaminant sampled in this study. Other contaminants present in the air that may have an effect on HRV such as carbon monoxide, nitrous oxide and ozone were not measured. Basic health questions were asked of each subject participating in the study; however, none of the subjects underwent a baseline physical examination. Therefore, we are not able to rule out undiagnosed medical conditions, such as heart disease, which may have affected the results. Previous studies have found beta-blockers increase HRV in patients following heart attacks (66, 67). Since most of our participants were young healthy adults, data was not collected on beta blocker drug use. Future studies should examine this possibility and carefully consider the use of beta-blocker medication as a potential confounder in assessing the effect of particulates exposures on HRV among elderly hypertensive e-waste workers.

Finally, noise is known to be negatively associated with HRV (68). Background noise levels were not measured, however, the temporary onsite clinic environment was conducive for reducing interferences due to background noise level. 


\section{Abbreviations}

HRV - heart rate variability

HF - high frequency power

LF - low frequency power

LF/HF - ratio of low frequency to high frequency power

RMSSD - root-mean square of successive differences

SDNN - standard deviation of normal RR intervals

BP-Blood pressure

SBP-Systolic blood pressure

DBP- Diastolic blood pressure

\section{Declarations}

\section{Ethics approval to participate}

The ethical and protocol review committee of the College of Health Sciences (CHS-Et/M.4-P 3.9/20152016), University of Ghana and the University of Michigan approved the study protocols. Permissions were also obtained from the e-waste association and community leaders of the study sites. Recruited participants provided a written informed consent endorsed by signature or thumbprint. All protocols were carried out in accordance with relevant guidelines and regulations.

Consent for publication: Not applicable.

Availability of data and materials: The datasets used and/or analysed during the current study are not publicly available due to privacy issues but are obtainable from the corresponding author on reasonable request.

Competing interest: The authors declare no conflict of interest. The funders had no role in the design of the study; data collection, analyses, or interpretation of data; in the writing of the manuscript, or in the decision to publish the results.

Funding: This study was financed by the $1 / 2$ West Africa-Michigan CHARTER in GEO-Health with funding from the United States National Institutes of Health/Fogarty International Center (US NIH/FIC) (paired grant no 1U2RTW010110-01/5U01TW010101) and Canada's International Development Research Center (IDRC) (grant no. 108121-001). 


\section{Authors contributions}

Conceptualization: AAAN, TGR, JNF and JAM; Methodology: AAAN, TGR, JNF. and JAM; Software: TGR; Investigation: AAAN, TGR., JNF, JAM, AAA, ST and LK; Validation and formal analysis: AAAN and DD; Resources: TGR and JNF; Data curation: AAAN, LK and DD; Writing-original draft preparation: AAAN; Writing-review and editing: AAAN, TGR, JNF, JAM, SB, AAA, ST and LK; Visualization: AAAN and DD; Supervision: TGR., JNF, and JAM; Project administration: TGR, and JNF; and Funding acquisition: TGR and JNF.

Acknowledgments: We sincerely acknowledge all our participants for voluntarily participating in the study. The leaders and chiefs of both study sites are duly acknowledged for their support. We also acknowledge the immense support from our research assistants for their invaluable help and hard work during the data collection period.

\section{Author Details}

1. Department of Biological, Environmental \& Occupational Health Sciences, School of Public Health, University of Ghana; P.O. Box LG13, Accra, Ghana.

2. Department of Biostatistics, School of Public Health, University of Ghana; P.O. Box LG13, Accra, Ghana.

3. Department of Environmental Health Sciences, University of Michigan, 1415 Washington Heights, Ann Arbor, MI 48109, USA.

4. Faculty of Agricultural and Environmental Sciences, McGill University, Montréal, QC H9X 3V9, Canada.

\section{References}

1. Adar SD, Gold DR, Coull BA, Schwartz J, Stone PH, Suh H. Focused exposures to airborne traffic particles and heart rate variability in the elderly. Epidemiology. 2007;18(1):95-103.

2. Hampel R, Rückerl R, Yli-Tuomi T, Breitner S, Lanki T, Kraus U, et al. Impact of personally measured pollutants on cardiac function. Int J Hyg Environ Health [Internet]. 2014;217(4):460-4. Available from: http://www.sciencedirect.com/science/article/pii/S1438463913001211

3. Paoin K, Ueda K, Seposo XT, Hayano J, Kiyono K, Ueda N, et al. Association between PM2.5 exposure and heart rate variability for the patients with cardiac problems in Japan. Air Qual Atmos Heal. 2020;13(3):339-47.

4. Kleiger RE, Stein PK, Bigger JT. Heart rate variability: Measurement and clinical utility. Ann Noninvasive Electrocardiol. 2005;10(1):88-101.

5. An Z, Jin Y, Li J, Li W, Wu W. Impact of Particulate Air Pollution on Cardiovascular Health. Curr Allergy Asthma Rep. 2018;18(3):3-9. 
6. Franchini M, Mannucci PM. Thrombogenicity and cardiovascular effects of ambient air pollution. Blood [Internet]. 2011 Sep 1 [cited 2020 Apr 26];118(9):2405-12. Available from: https://ashpublications.org/blood/article/118/9/2405/29501/Thrombogenicity-and-cardiovasculareffects-of

7. Elder SUA, Schulz WECH. Particles and Cardiovascular: mechanisms d. arrhythmias. In: flemming R Cassee, Nicholas LM, Newby D, editors. cardiovascular effects of inhaled ultrafine and nanosized particles. John Wiley and Sons Inc; 2011. p. 2-27.

8. Milojevic A, Wilkinson P, Armstrong B, Bhaskaran K, Smeeth L, Hajat S. No Title. Heart. 2014 Jul;100(14):1093-8.

9. Cornelissen VA, Verheyden B, Aubert AE, Fagard RH. Effects of aerobic training intensity on resting, exercise and post-exercise blood pressure, heart rate and heart-rate variability. J Hum Hypertens. 2010;24(3):175-82.

10. Pope CA. Epidemiology of fine particulate air pollution and human health: Biologic mechanisms and who's at risk? Environ Health Perspect. 2000;

11. Chuang K-J, Chan C-C, Su T-C, Lee C-T, Tang C-S. The effect of urban air pollution on inflammation, oxidative stress, coagulation, and autonomic dysfunction in young adults. Environ Health Perspect. 2013;176(1):370-6.

12. Gold DR, Litonjua A, Schwartz J, Lovett E, Larson A, Nearing B, et al. Ambient Pollution and Heart Rate Variability. Circulation. 2000;101:1267-73.

13. Huikuri H V., Stein PK. Heart rate variability in risk stratification of cardiac patients. Prog Cardiovasc Dis [Internet]. 2013;56(2):153-9. Available from: http://dx.doi.org/10.1016/j.pcad.2013.07.003

14. Stein PK, Bosner MS, Kleiger RE, Conger BM. Heart rate variability: A measure of cardiac autonomic tone. Am Heart J. 1994;127(5):1376-81.

15. Thayer JF, Yamamoto SS, Brosschot JF. The relationship of autonomic imbalance, heart rate variability and cardiovascular disease risk factors. Int J Cardiol [Internet]. 2010;141(2):122-31. Available from: http://dx.doi.org/10.1016/j.ijcard.2009.09.543

16. Hung C-S, Huang C-C, Pan S-C, Ma H-P, Huang C-C, Guo Y-LL, et al. Acute particulate matter exposure is associated with disturbances in heart rate complexity in patients with prior myocardial infarction. Sci Total Environ [Internet]. 2020;733:138842. Available from: http://www.sciencedirect.com/science/article/pii/S0048969720323597

17. Chen K, Wolf K, Breitner S, Gasparrini A, Stafoggia M, Samoli E, et al. Two-way effect modifications of air pollution and air temperature on total natural and cardiovascular mortality in eight European urban areas. Environ Int J. 2018;116(March):186-96.

18. Schneider A, Hampel R, Ibald-Mulli A, Zareba W, Schmidt G, Schneider R, et al. Changes in deceleration capacity of heart rate and heart rate variability induced by ambient air pollution in individuals with coronary artery disease. Part Fibre Toxicol. 2010;7:1-12.

19. Cavallari JM, Fang SC, Eisen EA, Schwartz J, Hauser R, Herrick RF, et al. Time Course of Heart Rate Variability Decline Following Particulate Matter Exposures in an Occupational Cohort Time Course of 
Heart Rate Variability Decline Following Particulate Matter Exposures in an Occupational Cohort. 2008;(May 2014).

20. Rajagopalan S, Al-Kindi SG, Brook RD. Air Pollution and Cardiovascular Disease: JACC State-of-theArt Review. J Am Coll Cardiol [Internet]. 2018 Oct 23;72(17):2054-70. Available from: https://doi.org/10.1016/j.jacc.2018.07.099

21. Riediker M, Franc Y, Bochud M, Meier R, Rousson V. Exposure to Fine Particulate Matter Leads to Rapid Heart Rate Variability Changes. Front Environ Sci. 2018 Jan;6(January):1-9.

22. Holguín F, Téllez-Rojo MM, Hernández M, Cortez M, Chow JC, Watson JG, et al. Air pollution and heart rate variability among the elderly in Mexico City. Epidemiology. 2003;14(5):521-7.

23. Lim YH, Bae HJ, Yi SM, Park EH, Lee BE, Hong YC. Vascular and cardiac autonomic function and PM2.5 constituents among the elderly: A longitudinal study. Sci Total Environ [Internet]. 2017;607608:847-54. Available from: http://dx.doi.org/10.1016/j.scitotenv.2017.07.077

24. Pieters N, Plusquin M, Cox B, Kicinski M, Vangronsveld J, Nawrot TS. An epidemiological appraisal of the association between heart rate variability and particulate air pollution: a meta-analysis. 2012;1127-35.

25. Pope CA, Dockery DW. Health effects of fine particulate air pollution: Lines that connect. J Air Waste Manag Assoc. 2006;

26. Zanobetti A, Gold DR, Stone PH, Suh HH, Schwartz J, Coull BA, et al. Reduction in heart rate variability with traffic and air pollution in patients with coronary artery disease. Environ Health Perspect. 2010;118(3):324-30.

27. Magari SR, Hauser R, Schwartz J, Williams PL, Smith TJ, Christiani DC. Association of heart rate variability with occupational and environmental exposure to particulate air pollution. Circulation. 2001;104(9):986-91.

28. Wu S, Deng F, Niu J, Huang Q, Liu Y, Guo X. The relationship between traffic-related air pollutants and cardiac autonomic function in a panel of healthy adults: a further analysis with existing data. 2011;23(February):289-303.

29. Cavallari JM, Eisen EA, Fang SC, Schwartz J, Hauser R, Herrick RF, et al. PM2.5 metal exposures and nocturnal heart rate variability: A panel study of boilermaker construction workers. Environ Heal A Glob Access Sci Source. 2008;7:1-8.

30. Wilson MD, McGlothlin JD, Rosenthal FS, Black DR, Zimmerman NJ, David Bridges C. The effect of occupational exposure to environmental tobacco smoke on the heart rate variability of bar and restaurant workers. J Occup Environ Hyg. 2010;7(7):D44-9.

31. Wu C, Kuo I, Su T, Li Y, Lin L, Chan C, et al. Original Contribution Effects of Personal Exposure to Particulate Matter and Ozone on Arterial Stiffness and Heart Rate Variability in Healthy Adults. 2010;171(12):1299-309.

32. Blacksmith Institute, blcksmith Institute. The worlds' Worst 2013: The Top Ten Toxic Threats Cleanup, Progress, and Ongoing Challenges. Accra; 2013. 
33. Akortia E, Olukunle OI, Daso AP, Okonkwo JO. Soil concentrations of polybrominated diphenyl ethers and trace metals from an electronic waste dump site in the Greater Accra Region, Ghana: Implications for human exposure. Ecotoxicol Environ Saf. 2017;137.

34. Tue NM, Takahashi S, Itai T, Asante KA. Soil contamination by halogenated polycyclic aromatic hydrocarbons from open burning of e-waste in Agbogbloshie (Accra, Ghana). J Mater Cycles Waste Manag : 2016;(May).

35. Asamoah A, Nikbakht M, Ko D, Muff J, Gydesen E, Nikbakht Fini M, et al. PAHs contamination levels in the breast milk of Ghanaian women from an e-waste recycling site and a residential area. Sci Total Environ [Internet]. 2019 May 20 [cited 2019 Oct 15];666:347-54. Available from: https://www.sciencedirect.com/science/article/pii/S0048969719306928

36. Asamoah A, Essumang DK, Muff J, Kucheryavskiy S V., Søgaard EG. Assessment of PCBs and exposure risk to infants in breast milk of primiparae and multiparae mothers in an electronic waste hot spot and non-hot spot areas in Ghana. Sci Total Environ. 2018;

37. Srigboh RK, Basu N, Stephens J, Asampong E, Perkins M, Neitzel RL, et al. Multiple elemental exposures amongst workers at the Agbogbloshie electronic waste (e-waste) site in Ghana. Chemosphere. 2016;164:68-74.

38. Kwarteng L, Baiden EA, Fobil J, Arko- J, Robins T, Batterman S. A ir Quality Impacts at an E-Waste Site in Ghana using Flexible, Moderate-Cost and Quality-Assured Measurements. 2020;0-2.

39. Ahiamadjie H. Characterization of Atmospheric Particulate Matter at E-waste Landfill Site. [Internet]. Semantic scholar. UNIVERSITY OF GHANA by; 2017. Available from: http://ugspace.ug.edu.gh/bitstream/handle/123456789/25848/Characterization of Atmospheric Particulate Matter at E-Waste Landfill Site in Agbogbloshie\%2C Accra.pdf?sequence $=1$ \&isAllowed $=$ y\%0Ahttps://pdfs.semanticscholar.org/820a/c3ad480b58ea26304d65dadc600f9

40. Amoabeng Nti, Asabea A, Arko-mensah J, Botwe PK, Dwomoh D, Kwarteng L, Takyi SA, et al. Effect of Particulate Matter Exposure on Respiratory Health of e-Waste Workers at Agbogbloshie, Accra, Ghana. Int J Environ Res Public Health. 2020;17(9):1-15.

41. Laskaris Z, Milando C, Batterman S, Mukherjee B, Basu N, O'Neill MS, et al. Derivation of TimeActivity Data Using Wearable Cameras and Measures of Personal Inhalation Exposure among Workers at an Informal Electronic-Waste Recovery Site in Ghana. Ann Work Expo Heal [Internet]. 2019 Jul 23;63(8):829-41. Available from: https://academic.oup.com/annweh/advancearticle/doi/10.1093/annweh/wxz056/5537141

42. Takyi SA, Basu N, Arko-Mensah J, Botwe P, Amoabeng Nti AA, Kwarteng L, et al. Micronutrient-rich dietary intake is associated with a reduction in the effects of particulate matter on blood pressure among electronic waste recyclers at Agbogbloshie, Ghana. BMC Public Health. 2020;20(1):1-14.

43. Brook RD, Rajagopalan S, Pope CA, Brook JR, Bhatnagar A, Diez-Roux A V., et al. Particulate matter air pollution and cardiovascular disease. Circulation. 2010 Jun 1;121(21):2331-78.

44. Ghana Statistical service. 2010 population and housing census report -urbanization [Internet]. Accra; 2014. Available from: /statsghana.gov.gh/gssmain/fileUpload/pressrelease/Urbanisation in 
Ghana.pdf

45. Akormedi M, Asampong E, Fobil JN. Working conditions and environmental exposures among electronic waste workers in Ghana. Int J Occup Environ Health. 2013;19(4):278-86.

46. Yu EA, Akormedi M, Asampong E, Meyer CG, Fobil JN. Informal processing of electronic waste at Agbogbloshie, Ghana: workers' knowledge about associated health hazards and alternative livelihoods. Glob Health Promot. 2017;

47. Oberhauser AM, Hanson KT. African Geographical Review Negotiating Livelihoods and Scale in the Context of Neoliberal Globalization: Perspectives from Accra, Ghana. 2007;(January 2015):37-41.

48. Oteng-Ababio M. Electronic Waste Management in Ghana - Issues and Practices. In: Sustainable Development - Authoritative and Leading Edge Content for Environmental Management. 2012.

49. Daum K, Stoler J, Grant RJ. Toward a more sustainable trajectory for e-waste policy: A review of a decade of e-waste research in Accra, Ghana. International Journal of Environmental Research and Public Health. 2017.

50. Task Force of The European Society of Cardiology and The North American, Society of Pacing and Electrophysiology. Heart rate variability Standards of measurement, physiological interpretation, and clinical use. Eur Heart J [Internet]. 1996;17:354-81. Available from: http://www.mendeley.com/research/guidelines-heart-rate-variability-2/

51. Hayano J, Ohashi K, Yoshida Y, Yuda E, Nakamura T, Kiyono K, et al. Increase in random component of heart rate variability coinciding with developmental and degenerative stages of life. Physiol Meas [Internet]. 2018;39(5):aac007. Available from: https://doi.org/10.1088/1361-6579/aac007

52. Zareba W, Nomura A, Couderc JP. Cardiovascular Effects of Air Pollution: What to Measure in ECG ? Environ Health Perspect. 2001;109(December 2000):533-8.

53. Keselman HJ, Algina J, Kowalchuk RK. The analysis of repeated measures designs: A review. Br J Math Stat Psychol. 2001;54(1):1-20.

54. Järvelin-Pasanen S, Sinikallio S, Tarvainen MP. Heart rate variability and occupational stresssystematic review. Ind Health. 2018;56:500-11.

55. Sammito S, Böckelmann I. Factors influencing heart rate variability. Int Cardiovasc Forum J. 2016;6:18-22.

56. Dekker J, Crow M, S R, Folsom AR, Hannan PJ, Liao D, et al. Low Heart Rate Variability in a 2-Minute Rhythm Strip Predicts Risk of Coronary Heart Disease and Mortality. Circulation [Internet]. 2000;120:1239-44. Available from: http://www.circulationaha.org

57. Roque AL, Valenti VE, Massetti T, Da Silva TD, Monteiro CBDM, Oliveira FR, et al. Chronic obstructive pulmonary disease and heart rate variability: A literature update. Int Arch Med. 2014;7(1):1-8.

58. Franco OS, Júnior AOS, Signori LU, Prietsch SOM, Zhang L. Cardiac autonomic modulation assessed by heart rate variability in children with asthma. Pediatr Pulmonol. 2020;55(6):1334-9.

59. Gong H, Linn WS, Terrell SL, Clark KW, Geller MD, Anderson KR, et al. Altered heart-rate variability in asthmatic and healthy volunteers exposed to concentrated ambient coarse particles. Inhal Toxicol. 
2004;16(6-7):335-43.

60. Riediker M. Cardiovascular Effects of Fine Particulate Matter Components in Highway Patrol Officers. Inhal Toxicol [Internet]. 2007 Jan 20 [cited 2019 Jul 7];19(sup1):99-105. Available from: http://www.tandfonline.com/doi/full/10.1080/08958370701495238

61. Riediker M, Devlin RB, Griggs TR, Herbst MC, Bromberg PA, Williams RW, et al. Cardiovascular effects in patrol officers are associated with fine particulate matter from brake wear and engine emissions. 2004;10:1-10.

62. Eninger RM, Rosenthal FS. Heart rate variability and particulate exposure in vehicle maintenance workers: A pilot study. J Occup Environ Hyg. 2004;1(8):493-9.

63. Dockery DW, III CAP, Kanner RE, Villegas GM, Schwartz J. Daily Changes in Oxygen Saturation and Pulse Rate Associated with Particulate Air Pollution and Barometric Pressure. Heal Eff Institute. 1999;(83).

64. Liao D, Creason J, Shy C, Williams R, Watfs R, Zweidinger R. Daily Variation of Particulate Air Pollution and Poor Cardiac Autonomic Control in the Elderly. 1999;107(7):521-5.

65. Creason J, Neas L, Walsh D, Williams R, Sheldon L, Liao D, et al. Particulate matter and heart rate variability among elderly retirees: The Baltimore 1998 PM study. J Expo Anal Environ Epidemiol. 2001;11(2):116-22.

66. Niemelä MJ, Airaksinen KEJ, Huikuri H V. Effect of Beta-blockade on heart rate variability in patients with coronary artery disease. J Am Coll Cardiol. 1994;23(6):1370-7.

67. Aronson D, Burger AJ. Effect of beta-blockade on heart rate variability in decompensated heart failure. Int J Cardiol. 2001;79(1):31-9.

68. Sim CS, Sung JH, Cheon SH, Lee JM, Lee JW, Lee J. The effects of different noise types on heart rate variability in men. Yonsei Med J. 2015;56(1):235-43.

\section{Figures}




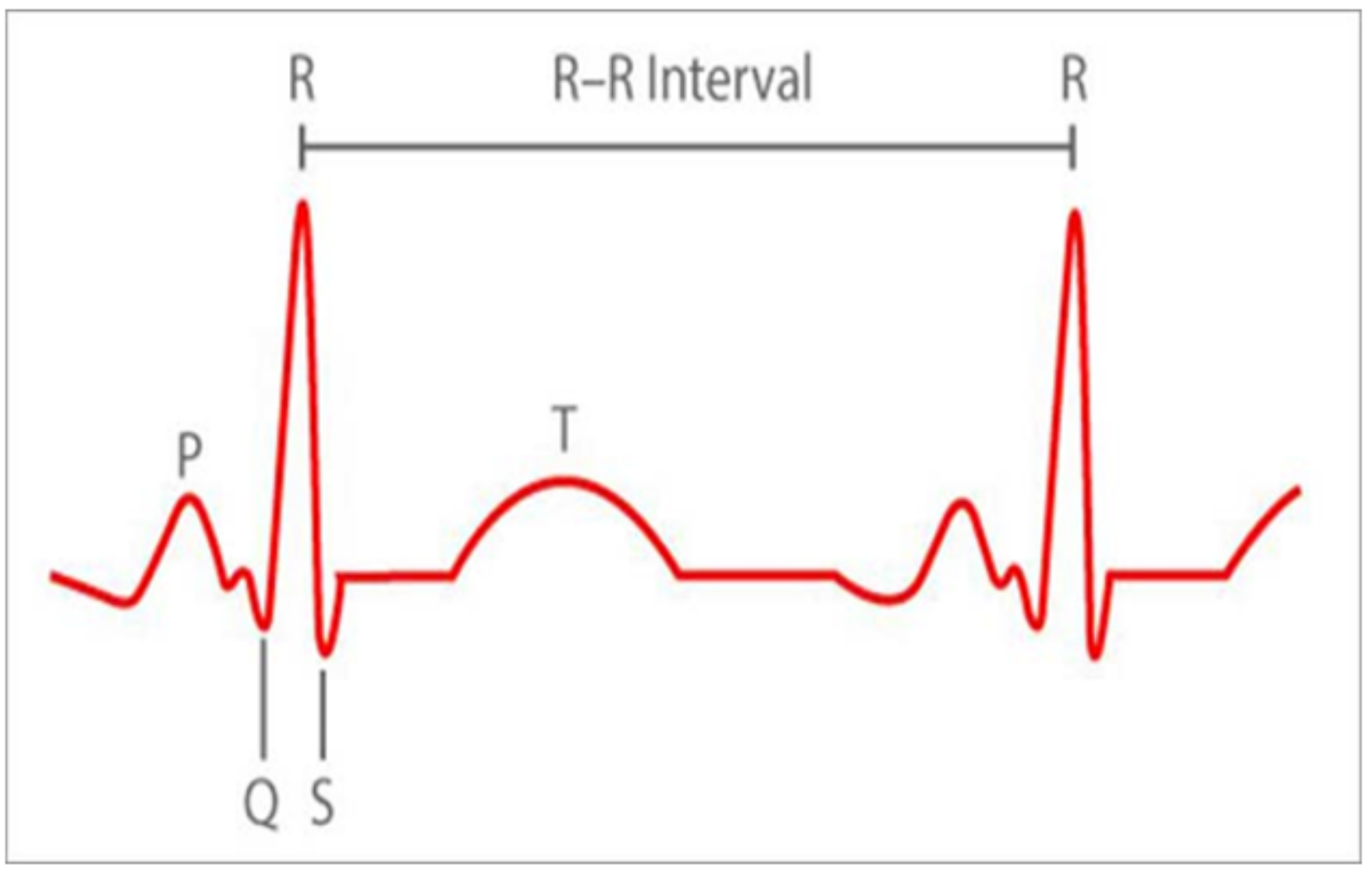

\section{Figure 1}

A typical ECG tracings showing the QRS complex (Wikimedia.org).

\section{Supplementary Files}

This is a list of supplementary files associated with this preprint. Click to download.

- Supplementarytables.docx 